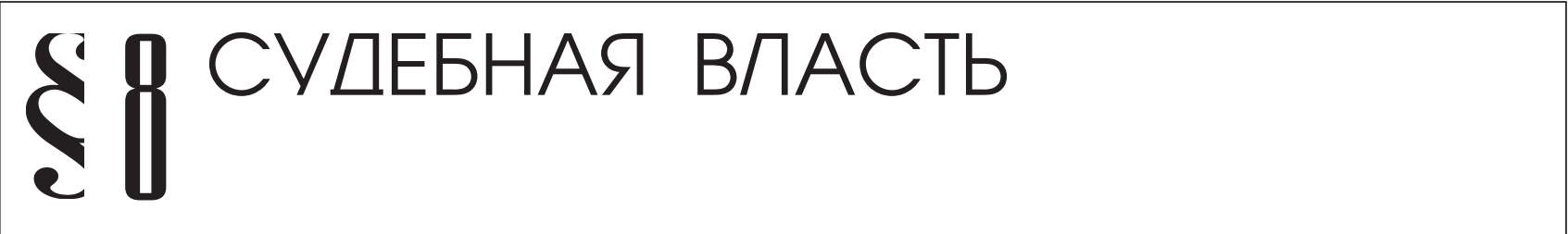

Ротар А.И.

\section{ФУНКЦИЯ ПОТЕРПЕВШЕГО В УГОЛОВНОМ ПРОЦЕССЕ России}

Аннотация: Предметом исследования выступают нормы уголовно-прочессуального законодательства России, решения Конституиионного Суда Российской Федераиии, регулирующие проиессуальное положение потерпевщего в уголовном процессе России, в том числе, отражающие его место в числе других участников, выполняемую функиию в ходе уголовного судопроизводства, соотночение правовых категорий «обвинение» и «уголовное преследование», особенности в реализации отдельных направлений деятельности, а также теоретические разработки указанных вопросов, в частности, научные статьи, диссертационные исследования и монографии известных ученых процессуалистов. Методологической основой являются общенаучные методы, такие как анализ и синтез, метод системного подхода, а также основные кониептуальные положения современной доктрины уголовно-процессуального права Проведенное исследование показывает, что некоторые авторы называют функиией потерпевщего - «обвинение», другие - «уголовное преследование»; в статье проведено соотномение данных категорий и сделан вывод о том, что «уголовное преследование» необходимо рассматривать как составную часть функиии «обвинения». Проведенньй анализ «обвинения» как функиии позволил прийти к выводу о ее содержании, в которое входят: - уголовное преследование, - формулирование (предъявление) обвинения, - поддержание обвинения перед судом. Данные направления деятельности должны быть признаны подфункииями основной функиии обвинения. Особенность процессуального статуса потерпевщего позволяет отметить его возможности в реализации обозначенных видов процессуальной деятельности.В результате сделан вывод о том, что являясь основным участником уголовного судопроизводства, потерпевший выполняет функцию обвинения, при этом, в силу публичности уголовного процесса, обязанность по защите и восстановлению нарушенных или ограниченных прав потерпевших возлагается на государственные органы и должностных лии, которые обязаны возбудить уголовное дело, привлечь лицо в качестве обвиняемого, поддержать государственное обвинение в суде.Также в статье предлагается новая редакиия ст. 22 УПК РФ, название и содержание которой должны быть приведены в соответствие с другими нормами УПК РФ, а также с предлагаемым в статье правовым пониманием функции «обвинения».

Abstract: The object of studies involves norms of international criminal legislation of Russia, decisions of the Constitutional Court of the Russian Federation, regulating procedural position of a victim in the criminal process of Russia, including analysis of role of victim among other participants, implemented function in the course of criminal judicial proceedings, correlation of the legal categories of "accusation" and "criminal prosecution", specific features of implementation of specific directions of activities, as well as theoretical developments in this sphere, including scientific articles, dissertation studies and monographs of renowned procedural scholars. The methodological basis includes general scientific methods, such as a analysis and synthesis, method of systemic approach, as well as main conceptual provisions of the modern doctrine of international criminal law. The studies show that some authors call the function of a victim "accusation", and others refer to "criminal prosecution". The author analyzes the correlation of these categories drawing a conclusion that "criminal prosecution" should be regarded as part of "accusation". The analysis of "accusation" as a function has allowed to draw a conclusion on its contents: criminal prosecution, formulation (presenting) an accusation, support of accusation in court. These directions of activities should be regarded as sub-functions of the main function of accusation. Specific features of procedural status of a victim allows to single out his capabilities in the sphere of said types of procedural activity. As a result a conclusion is made that while being the main participant of criminal judicial proceedings, the victim is one of the key participants of a trial, the official bodies and officers implement an obligation on protection and restoration of violated or limited rights, being obliged to initiate a criminal case, establish an accused person and support prosecution in trial. The article also offers a new text of Art. 22 of the Criminal Procedural Code of the Russian Federation, the author considers that its title and contents should conform to other norms of the Criminal Procedural Code of the Russian Federation and the legal understanding of function of "accusation" as provided for in this article. 
DOI: $10.7256 / 1811-9018.2014 .8 .12622$

При цитировании этой статьи сноска на доі обязательна

\section{Право и политика $8(176) \cdot 2014$}

Ключевые слова: Потерпевиий, функции, подфункции, интерес, публичность, обвинение, уголовное преследование, уголовное судопроизводство, процессуальный статус, поддержание обвинения.

Keywords: Victim, functions, sub-functions, interest, public prosecution, criminal prosecution, criminal judicial proceedings, procedural status, supporting prosecution.

в ще в советский период времени ученые задались вопросом о том, какие функции выполняют те или иные субъекты уголовного процесса, «первоначально разработка проблемы процессуальных функций в советской правовой науке была предпринята в связи с задачей обоснования демократического принципа состязательности», писал А.М. Ларин ${ }^{1}$.

Как в советской доктрине уголовного процесса, так и в настоящее время нет единого мнения о системе уголовно-процессуальных функций, при этом большинство ученых придерживаются концепции трех основных функций: обвинения, защиты и разрешения дела²

Под функциями в уголовном судопроизводстве мы предлагаем понимать направление деятельности, которое лежит в основе процессуального статуса участника уголовного процесса в ходе производства по уголовному делу, которое направлено на решение как общего назначения уголовного процесса, так и отдельных задач в определенной стадии (возбуждения уголовного дела, предварительного расследования, судебного разбирательства, стадий обжалования судебного решения).

В осуществлении функции задействованы все участники стороны (обвинения или защиты), однако каждый из них преследует свой собственный интерес - либо общественный (государственный) либо частный, для реализации которого каждый из участников наделяется различными по объему и содержанию полномочиями либо правами. Таким образом, содержание функции состоит из совокупности полномочий (должностных лиц, государственных органов) либо прав (физических и юридических лиц).

Потерпевший - как центральная фигура уголовного судопроизводства относится к стороне обвинения (гл. 6 УПК РФ). Вопрос о функции, выполняемой потерпевшим в ходе уголовного судопроизводства, исследуется в научной литературе довольно часто. Некоторые ав-

\footnotetext{
${ }^{1}$ Ларин А.М. Расследование по уголовному делу: процессуальные функции. - М.: Юридическая литература, 1986. - С. 6.

${ }^{2}$ Бозров В.М. К проблеме методологии в теории процессуальных функций // Российский юридический журнал. 2011. N 3. С. 170; Бородинова Т.Г. Сторона защиты и ее функция в судебных стадиях уголовного судопроизводства. - Краснодар, 2009. - С. 53; Ягофаров Ф.М. Механизм реализации функции обвинения при рассмотрении дела судом первой инстанции. Дисс.канд.юрид. наук. - Оренбург, 2003. - С. 14-15 и др.
}

торы полагают, что потерпевший выполняет функцию обвинения ${ }^{3}$.

И.В. Коркина, например, занимает иную позицию: «Выполняемая потерпевшим в уголовном процессе функция не может быть безусловно названа функцией обвинения либо функцией поддержания гражданского иска. Потерпевший... осуществляет функцию... достижения своих личных интересов..., интерес потерпевшего выражается в скорейшем и полном возмещении (компенсации) причиненного преступлением вреда либо восстановлении предшествующего совершению преступления состояния...» ${ }^{4}$.

Нам представляется ошибочным понимание функции, выполняемой потерпевшим через его законный интерес, который может быть либо таким, каким его называет автор, либо может быть абсолютно иным, например, потерпевший не требует возмещения вреда (это его субъективное право), а восстановление предшествующего состояния невозможно (по фактам причинения вреда здоровью, по деяниям, в которых объектом посягательства стали половая свобода или неприкосновенность и другие). При этом потерпевший настаивает именно на наказании подсудимого путем лишения свободы на определенный срок или пожизненно. «Достижение личных интересов» не может быть функцией потерпевшего, поскольку под функцией должно пониматься направление деятельности участников уголовного судопроизводства, а достижение личных интересов - это цель участия в уголовном процессе. Все участники стороны обвинения и защиты преследуют либо личные либо общественные (государственные) интересы, но не наличие единого интереса, а именно выполнение общей функции является основанием для включения того или иного участника в сторону обвинения или защиты.

\footnotetext{
${ }^{3}$ Величко И.В. Понятие потерпевшего и его процессуально-правовой статус по действующему уголовно-процессуальному законодательству Российской Федерации // Общество и право. - 2011. - N 4. - С. 232; Колуказакова Е.В. Участие потерпевшего, его представителя в уголовном преследовании по делам публичного обвинения. Автореф...канд.юрид.наук. Н.Новгород, 2008. - С. 12-13.

${ }^{4}$ Коркина И.В. Процессуальное положение потерпевшего в досудебном уголовном судопроизводстве. Автореф...канд.юрид. наук. - М., 2006. - С. 16.
} 
В литературе встречается и позиция, согласно которой потерпевший выполняет не функцию обвинения, а уголовного преследования. Так, И.В. Жеребятьев полагает, что «осуществление потерпевшим обвинительной деятельности...будет выступать лишь одной из форм уголовного преследования. Кроме того, в качестве одной из форм осуществления потерпевшим функции уголовного преследования будет выступать и деятельность по предъявлению и поддержанию гражданского иска» 5 .

В основе столь разного понимания авторами функции потерпевшего лежит различное отношение к содержанию правовых понятий «обвинение», «уголовное преследование». В данном случае И.В. Жеребятьев исходит из того, что категория «уголовное преследование» шире категории «обвинение».

По нашему мнению категорию «обвинение» необходимо различать в широком и в узком смысле. В широком смысле обвинение представляет собой всю деятельность участников стороны обвинения (и поэтому должно рассматриваться как функция), осуществляемая при производстве по уголовному делу (она включает в себя и инициацию уголовного преследования; его последующее осуществление в целях изобличения подозреваемого, обвиняемого; формулирование и выдвижение обвинения в суде, а также его поддержание). В узком смысле обвинение это деятельность по формулированию, выдвижению и поддержанию обвинения в судебных стадиях (и поэтому должно рассматриваться как право конкретного участника стороны обвинения).

Уголовное преследование - начальный этап деятельности по обвинению лица в совершении преступления, формулирование обвинения осуществляется в стадии расследования, окончательно оформляется в обвинительном заключении (акте, постановлении), поддержание обвинения - основное содержание деятельности участников стороны обвинения в судебных стадиях. С учетом сказанного, уголовное преследование мы считаем содержанием функции обвинения, его составной частью.

Представляет интерес позиция Конституционного Суда РФ (далее КС РФ): «функции разрешения уголовного дела и функция обвинения должны быть строго разграничены, каждая из них возлагается на соответствующий субъект. Возбуждение уголовного преследования, формулирование обвинения и его поддержание

\footnotetext{
${ }^{5}$ Жеребятьев И.В. Личность потерпевшего в современном уголовном судопроизводстве России: Монография. - Оренбург: РИК ГОУ ОГУ, 2004. - С. 75.
}

перед судом обеспечиваются указанными в законе органами и должностными лицами, потерпевшими» ${ }^{6}$.

Таким образом, КС РФ определил содержание уголовно-процессуальной функции обвинения, по нашему мнению именно из данных элементов процессуальной деятельности состоит функция обвинения, выполняемая участниками уголовного судопроизводства, выступающими на стороне обвинения: - уголовное преследование, - формулирование (предъявление) обвинения, - поддержание обвинения перед судом.

Данные направления деятельности, как лежащие в основе функции обвинения, таким образом, должны быть признаны содержанием функции обвинения или подфункциями.

В юридической литературе позиция о существовании подфункций основной функции высказывалась Д.М. Беровой, которая выделяет три основные функции - обвинения, защиты и правосудия, а также ряд подфункций (подсистем), относящихся к каждой из основных уголовно-процессуальных функций?

В соответствии со ст. 22 УПК РФ потерпевший вправе участвовать в уголовном преследовании обвиняемого, а по уголовным делам частного обвинения - выдвигать и поддерживать обвинение в порядке, установленном УПК РФ.

КС РФ в постановлении от 02.07.2013 г. № 16-П уточнил: «Для участия в уголовном преследовании по делам публичного и частно-публичного обвинения потерпевший наделен правами знать о предъявленном обвиняемому обвинении и знакомиться с материалами дела, заявлять ходатайства и отводы, представлять доказательства, выступать в судебных прениях, обжаловать решения суда (часть вторая статьи 42)» ${ }^{8}$. Тем самым КС РФ показал, что уголовное преследование - направление деятельности, реализуемое через предоставление конкретных процессуальных прав.

Поскольку уголовное преследование представляет собой процессуальную деятельность, осуществляемую

\footnotetext{
${ }^{6}$ Постановление КС РФ от 27 июня 2005 г. № 7-П «По делу о проверке конституционности положений ч. 2 и 4 ст. 20 , ч. 6 ст. 144 , п.3 ч. 1 ст. 145 , ч. 3 ст. 318 , ч. 1 и 2 ст. 319 УПК РФ в связи с запросами Законодательного Собрания Республики Карелия и Октябрьского районного суда г. Мурманска» // СЗ РФ. - 2005. - № 28. - Ст. 2904.

${ }^{7}$ Берова Д.М. Понятие и система функций в уголовном судопроизводстве // Общество и право. - 2010. - N 4. - С. 224 - 232.

8 Постановление Конституционного Суда РФ от 02.07.2013 № 16-П «По делу о проверке конституционности положений части первой статьи 237 Уголовно-процессуального кодекса Российской Федерации в связи с жалобой гражданина Республики Узбекистан Б.Т. Гадаева и запросом Курганского областного суда» // С3 РФ. - 2013. - № 28. - Ст. 3881.
} 
DOI: $10.7256 / 1811-9018.2014 .8 .12622$

При цитировании этой статьи сноска на доі обязательна

\section{Право и политика 8 (176) 2014}

стороной обвинения в целях изобличения подозреваемого, обвиняемого в совершении преступления (п. 55 ст. 5 УПК РФ), потерпевший как участник стороны обвинения вправе осуществлять уголовное преследование лица в целях его изобличения. Поэтому совершенно справедливо указание на участие потерпевшего в уголовном преследовании обвиняемого в ст. 22 УПК РФ.

Однако, поскольку уголовное преследование - начальная деятельность стороны обвинения, связанная с изобличением лица, причастного к совершению преступления, неясно, почему законодатель говорит только о праве на уголовное преследование обвиняемого, но не подозреваемого, хотя совершенно очевидно, что при подаче заявления о возбуждении уголовного дела в отношении конкретного лица, потерпевший реализует деятельность по уголовному преследованию подозреваемого.

Кроме того, нам представляется, что содержание статьи 22 УПК РФ является неполным также потому, что в ней право потерпевшего поддерживать обвинение предусмотрено только по уголовным делам частного обвинения. Такая норма противоречит общему положению потерпевшего, как участника стороны обвинения, а также п. 16 ч. 2 ст. 42 УПК РФ, согласно которого потерпевший вправе «поддерживать обвинение». Поскольку права потерпевшего, закрепленные в ст. 42 УПК РФ распространяются на потерпевших по уголовным делам любой категории, соответственно, в ст. 22 УПК РФ также должно быть закреплено данное право.

На этом основании, считаем, что в ст. 22 УПК РФ должны быть внесены дополнения: «Потерпевший, его законный представитель и (или) представитель вправе участвовать в уголовном преследовании подозреваемого и обвиняемого, в доказывании их причастности к совершению преступления, а также в поддержании обвинения в судебных стадиях, а по уголовным делам частного обвинения - выдвигать и поддерживать обвинение в порядке, установленном настоящим Кодексом». Изменению подлежит и название ст. 22 УПК РФ «Право потерпевшего на участие в обвинении и уголовном преследовании».

Итак, потерпевший в уголовном процессе выполняет функцию обвинения, которая состоит из деятельности по уголовному преследованию, формулированию (предъявлению обвинения), а также по его поддержанию в суде. Каждое из названных видов деятельности должно быть признано подфункциями основной функции обвинения.

Особенность статуса потерпевшего отражается в его возможностях по реализации обозначенных видов деятельности (подфункций), среди которых нужно от- метить следующие: потерпевший может инициировать уголовное преследование (подав заявление о возбуждении уголовного дела), может принимать участие в доказывании, вправе поддерживать обвинение в суде наравне с государственным обвинителем.

Однако, в литературе отмечается, и, является, безусловно, важным то, что сам потерпевший не наделяется правом предопределять необходимость осуществления уголовного преследования, такое право принадлежит только государству ${ }^{9}$. К такому выводу пришел КС РФ, в ряде решений которого отражается следующая позиция: «Обязанность государства обеспечивать права потерпевших от преступлений не предполагает наделение их правом определять необходимость осуществления публичного уголовного преследования в отношении того или иного лица, а также пределы возлагаемой на это лицо уголовной ответственности и наказания» (Постановление от 18.03.2014 г. № 5-П). В другом Постановлении от 02.07.2013 г. № 16-П сказано: «В силу особенностей своего статуса потерпевший не наделяется правом предопределять осуществление уголовного преследования по делам публичного и частнопубличного обвинения и его пределы и самостоятельно выдвигать и поддерживать обвинение в суде».

Также в силу особенностей публичного уголовного процесса, потерпевший не принимает участия в формулировании обвинения, согласно ст. 171 и 172 УПК РФ - привлечение в качестве обвиняемого и предъявление обвинения - возлагается на следователя, потерпевший имеет лишь право знать о предъявленном обвиняемому обвинении (п. 1 ч. 2 ст. 42 УПК РФ); аналогичным образом при составлении обвинительного акта и обвинительного постановления в дознании (ст. 225 и ст. 226.7 УПК РФ) полномочия по формулированию обвинения возлагается на дознавателя.

Публичность уголовного судопроизводства возлагает на государство также обязанность поддерживать выдвинутое обвинение в суде, для чего в судебном разбирательстве обвинение от имени государства поддерживает государственный обвинитель, участие которого является обязательным по уголовным делам публичного и частно-публичного обвинения (ч. 2 ст. 246 УПК РФ). Потерпевший в судебном разбирательстве наделяется правом поддерживать обвинения наряду с государственным обвинителем (п. 16 ч. 2 ст. 42 УПК РФ), в том числе, может выступать в прениях (ч. 2

\footnotetext{
${ }^{9}$ Федотов A.B. Уголовное преследование виновного как гарантия охраны прав и законных интересов лиц, потерпевших от преступления // Уголовное судопроизводство. - 2009. - N 3. - С. 16.
} 
DOI: $10.7256 / 1811-9018.2014 .8 .12622$

При цитировании этой статьи сноска на dоі обязательна

Судебная власть

ст. 292 УПК РФ), при этом при неявке потерпевшего суд рассматривает уголовное дело в его отсутствие, за исключением случаев, когда его явка признается судом обязательной (ч. 2 ст. 249 УПК РФ).

Следует согласиться с Е.В. Колуказаковой, утверждающей, что «обвинение, поддерживаемое потерпевшим по делу публичного обвинения, будет неизбежно вторичным, производным от государственного обвинения, выдвинутого и поддерживаемого обвинительной властью государства» ${ }^{10}$.

Таким образом, являясь основным участником уголовного судопроизводства, потерпевший выполняет функцию обвинения, при этом, в силу публичности уголовного процесса, обязанность по защите и восстановлению нарушенных или ограниченных прав потерпевших возлагается на государственные органы и должностных лиц, которые обязаны возбудить уголовное дело, привлечь лицо в качестве обвиняемого, поддержать государственное обвинение в суде.

\section{Библиография:}

1. Берова, Д. М. Понятие и система функций в уголовном судопроизводстве [Текст] / Д. М. Берова // Общество и право. - 2010. - N 4. - С. 224-232.

2. Бозров, В. М. К проблеме методологии в теории процессуальных функций [Текст] / В. М. Бозров // Российский юридический журнал. - 2011. - N 3. - C. 166-172.

3. Бородинова, Т. Г. Сторона защиты и ее функция в судебных стадиях уголовного судопроизводства [Текст] / Т. Г. Бородинова. - Краснодар: ГОУ ВПО «Российская академия правосудия», 2009. - 208 с.

4. Величко, И. В. Понятие потерпевшего и его процессуально-правовой статус по действующему уголовно-процессуальному законодательству Российской Федерации [Текст] / И.В. Величко // Общество и право. - 2011. - N 4. - С. 232-237.

5. Жеребятьев, И. В. Личность потерпевшего в современном уголовном судопроизводстве России [Текст] / И. В. Жеребятьев. Монография. Оренбург: РИК ГОУ ОГУ, 2004. - 220 с.

6. Колуказакова, Е. В. Участие потерпевшего, его представителя в уголовном преследовании по делам публичного обвинения [Текст] : автореф. дис. канд. юрид. наук / Е. В. Колуказакова. - 12.00.09. - Н.Новгород, 2008. - 34 с.

\footnotetext{
${ }^{10}$ Колуказакова Е.В. Указ.соч. С. 7-8.
}

7. Коркина, И. В. Процессуальное положение потерпевшего в досудебном уголовном судопроизводстве [Текст] : автореф. дис. канд. юрид. наук / И. В. Коркина. - 12.00.09. - М., 2006. - 32 с.

8. Ларин, А. М. Расследование по уголовному делу: процессуальные функции [Текст] / А. М. Ларин. М.: Юридическая литература, 1986. - 160 с.

9. По делу о проверке конституционности положений части первой статьи 237 Уголовно-процессуального кодекса Российской Федерации в связи с жалобой гражданина Республики Узбекистан Б.Т. Гадаева и запросом Курганского областного суда [Текст]: [Постановление Конституционного Суда РФ от 02 июля 2013 № 16-П] // С3 РФ. - 2013. - № 28. Ст. 3881. - С. 7696-7707.

10. По делу о проверке конституционности части 2.1 ст. 399 УПК РФ в связи с запросом Кетовского районного суда Курганской области [Текст]: [Постановление Конституционного суда РФ от 18 марта 2014 г. № 5-П] // С3 РФ. - 2014. - № 13. Ст. 1526. - С. 3297-3304.

11. Федотов, А. В. Уголовное преследование виновного как гарантия охраны прав и законных интересов лиц, потерпевших от преступления [Текст] / А. В. Федотов // Уголовное судопроизводство. - 2009. - N 3. - C. 14-18.

12. Ягофаров, Ф. М. Механизм реализации функции обвинения при рассмотрении дела судом первой инстанции [Текст] : дис. канд. юрид. наук / Ф. М. Ягофаров. - 12.00.09. - Оренбург, 2003. - 150 с.

13. О. А. Тарнавский, О. С. Акулин Отдельные проблемные вопросы относительно процессуальной фигуры потерпевшего в уголовном судопроизводстве России // Право и политика. - 2011. - 12. - С. 2053-2056.

14. О.Н. Селедникова Проблемы обеспечения взыскания гражданского иска в уголовном судопроизводстве // Право и политика. - 2012. - 12. - С. 2057-2060.

15. Федорченко А.А.. Правовое положение жертвы преступления как свидетеля в международном уголовном процессе // Международное право и международные организации / International Law and International Organizations. - 2014. - № 1. C. 104-107. DOI: 10.7256/2226-6305.2014.1.11556

16. Титов П.С.. Об участии защитника в собирании доказательств // Политика и Общество. - 2013. - № 6. - C. 104-107. DOI: 10.7256/1812-8696.2013.6.8077

17. Глушков А.И.. Роль прокурора в обеспечении реализации принципа состязательности сторон на досудебных стадиях уголовного процесса 


\section{Право и политика $8(176) \cdot 2014$}

// Административное и муниципальное право. - 2013. - № 5. - C. 104-107. DOI: 10.7256/19992807.2013.05.14

18. Винокуров А.Ю.. Административное преследование как функция прокуратуры Российской Федерации // Административное и муниципальное право. - 2012. - № 10. - С. 104-107.

19. Федорченко А.А. Процессуальные права пострадавших в судебных разбирательствах международных уголовных трибуналов ad hoc // NB: Вопросы права и политики. - 2014. - № 4. - С.208-224. DOI: 10.7256/2305-9699.2014.4.11695. URL: http://enotabene.ru/lr/article_11695.html

20. Кабанов П.А. Криминальная политическая виктимология как межотраслевая криминологическая теория: понятие, предмет, структура и перспективы развитя в современной России // NB: Вопросы права и политики. - 2012. - № 5. - C.218-232. DOI: 10.7256/2305-9699.2012.5.201. URL: http://e-notabene. $\mathrm{ru} / \mathrm{lr} /$ article 201.html

21. Трунов И.Л., Айвар Л.К.. Решение по делу о ДТП на Ленинском проспекте г. Москвы гарантирует судебную защиту умершим подозреваемым // Полицейская деятельность. - 2011. - № 5. C. $104-107$

22. О. А. Тарнавский, О. С. Акулин Отдельные проблемные вопросы относительно процессуальной фигуры потерпевшего в уголовном судопроизводстве России // Право и политика. - 2011. - 12. C. $2053-2056$.

\section{References (transliteration):}

1. Berova, D. M. Ponyatie i sistema funktsii v ugolovnom sudoproizvodstve [Tekst] / D. M. Berova // Obshchestvo i pravo. $-2010 .-$ N 4. - S. 224-232.

2. Bozrov, V. M. K probleme metodologii $\mathrm{v}$ teorii protsessual'nykh funktsii [Tekst] / V. M. Bozrov // Rossiiskii yuridicheskii zhurnal. - 2011. - N 3. - S. 166-172.

3. Borodinova, T. G. Storona zashchity $\mathrm{i}$ ee funktsiya $\mathrm{v}$ sudebnykh stadiyakh ugolovnogo sudoproizvodstva [Tekst] / T. G. Borodinova. - Krasnodar: GOU VPO «Rossiiskaya akademiya pravosudiya», 2009. - 208 s.

4. Velichko, I. V. Ponyatie poterpevshego i ego protsessual'no-pravovoi status po deistvuyushchemu ugolovno-protsessual'nomu zakonodatel'stvu Rossiiskoi Federatsii [Tekst] / I.V. Velichko // Obshchestvo i pravo. - 2011. - N 4. - S. 232-237.
5. Zherebyat'ev, I. V. Lichnost' poterpevshego v sovremennom ugolovnom sudoproizvodstve Rossii [Tekst] / I. V. Zherebyat'ev. Monografiya. - Orenburg: RIK GOU OGU, 2004. - $220 \mathrm{~s}$.

6. Kolukazakova, E. V. Uchastie poterpevshego, ego predstavitelya $\mathrm{v}$ ugolovnom presledovanii po delam publichnogo obvineniya [Tekst] : avtoref. dis. kand. yurid. nauk / E. V. Kolukazakova. - 12.00.09. - N.Novgorod, 2008. $-34 \mathrm{~s}$.

7. Korkina, I. V. Protsessual'noe polozhenie poterpevshego $\mathrm{v}$ dosudebnom ugolovnom sudoproizvodstve [Tekst] : avtoref. dis. kand. yurid. nauk / I. V. Korkina. - 12.00.09. - M., 2006. - $32 \mathrm{~s}$.

8. Larin, A. M. Rassledovanie po ugolovnomu delu: protsessual'nye funktsii [Tekst] / A. M. Larin. - M.: Yuridicheskaya literatura, 1986. - $160 \mathrm{~s}$.

9. Fedotov, A. V. Ugolovnoe presledovanie vinovnogo kak garantiya okhrany prav i zakonnykh interesov lits, poterpevshikh ot prestupleniya [Tekst] / A. V. Fedotov // Ugolovnoe sudoproizvodstvo. - 2009. - N 3. - S. 14-18.

10. Yagofarov, F. M. Mekhanizm realizatsii funktsii obvineniya pri rassmotrenii dela sudom pervoi instantsii [Tekst] : dis. kand. yurid. nauk / F. M. Yagofarov. - 12.00.09. - Orenburg, 2003. - $150 \mathrm{~s}$.

11. O. A. Tarnavskii, O. S. Akulin Otdel'nye problemnye voprosy otnositel'no protsessual'noi figury poterpevshego v ugolovnom sudoproizvodstve Rossii // Pravo i politika. - 2011. - 12. - C. 2053-2056.

12. O.N. Selednikova Problemy obespecheniya vzyskaniya grazhdanskogo iska v ugolovnom sudoproizvodstve // Pravo i politika. - 2012. - 12. - C. 2057-2060.

13. Fedorchenko A.A.. Pravovoe polozhenie zhertvy prestupleniya kak svidetelya $\mathrm{v}$ mezhdunarodnom ugolovnom protsesse // Mezhdunarodnoe pravo i mezhdunarodnye organizatsii / International Law and International Organizations. - 2014. - № 1. - S. 104107. DOI: $10.7256 / 2226-6305.2014 .1 .11556$

14. Titov P.S.. Ob uchastii zashchitnika v sobiranii dokazatel'stv // Politika i Obshchestvo. - 2013. - № 6. - S. 104-107. DOI: 10.7256/18128696.2013.6.8077

15. Glushkov A.I.. Rol' prokurora v obespechenii realizatsii printsipa sostyazatel'nosti storon na dosudebnykh stadiyakh ugolovnogo protsessa // Administrativnoe i munitsipal'noe pravo. - 2013. - № 5. - S. 104-107. DOI: 10.7256/1999-2807.2013.05.14

16. Vinokurov A.Yu.. Administrativnoe presledovanie kak funktsiya prokuratury Rossiiskoi Federatsii // Administrativnoe i munitsipal'noe pravo. - 2012. № 10. - S. 104-107. 
DOI: $10.7256 / 1811-9018.2014 .8 .12622$

При цитировании этой статьи сноска на dоі обязательна

Судебная власть

17. Fedorchenko A.A. Protsessual'nye prava postradavshikh v sudebnykh razbiratel'stvakh mezhdunarodnykh ugolovnykh tribunalov ad hoc // NB: Voprosy prava i politiki. - 2014. - № 4. - S.208-224. DOI: 10.7256/2305-9699.2014.4.11695. URL: http://e-notabene.ru/lr/article_11695.html

18. Kabanov P.A. Kriminal'naya politicheskaya viktimologiya kak mezhotraslevaya kriminologicheskaya teoriya: ponyatie, predmet, struktura i perspektivy razvitya v sovremennoi Rossii // NB: Voprosy prava i politiki. - 2012. - № 5. - S.218-232. DOI: 10.7256/2305-
9699.2012.5.201. URL: http://e-notabene.ru/lr/article 201.html

19. Trunov I.L., Aivar L.K.. Reshenie po delu o DTP na Leninskom prospekte g. Moskvy garantiruet sudebnuyu zashchitu umershim podozrevaemym // Politseiskaya deyatel'nost'. - 2011. - № 5. S. 104-107

20. O. A. Tarnavskii, O. S. Akulin Otdel'nye problemnye voprosy otnositel'no protsessual'noi figury poterpevshego v ugolovnom sudoproizvodstve Rossii // Pravo i politika. - 2011. - 12. - C. $2053-2056$. 